\title{
ANALISIS KEUNTUNGAN INVESTASI EMAS DENGAN IHSG
}

\author{
Ihsan Kurniawan \\ Program Studi Magister Manajemen Universitas Tarumanagara \\ ihsan.1x4n@gmail.com
}

\begin{abstract}
Before investing, investors should do return of investment analysis. This study is to determine the differences of return between gold investment and IHSG stock. This study period is between November 2009 to October 2018 with timespan of 1 year, 5 years, and 10 years. The data used for this study is IHSG stock prices historical data, and the price of LBMA gold. Data analysis using T-test (independent sample t-test). The results of this study shows that investing in gold instrument return higher profit than investing in IHSG stocks.
\end{abstract}

Abstrak : Sebelum berinvestasi, investor perlu melakukan analisa terhadap return dari investasi yang akan dipilih. Penelitian ini bertujuan untuk membandingkan return antara investasi emas dengan investasi Indeks Harga Saham Gabungan (IHSG). Periode penelitian yang digunakan adalah antara November 2009 sampai dengan Oktober 2018 dengan rentang waktu 1 tahun, 5 tahun, dan 10 tahun. Data yang digunakan adalah data historis harga IHSG dan harga emas dunia. Analisis data menggunakan uji-T (independent sample t-test). Hasil dari penelitian ini menunjukkan bahwa investasi emas menghasilkan return lebih tinggi dibandingkan return IHSG.

Keywords - Investment, gold, stocks, return

\section{PENDAHULUAN \\ Latar Belakang}

Emas merupakan komoditi investasi tradisional yang sudah diperjualbelikan sejak zaman dahulu. Emas atau biasa disebut logam mulia juga merupakan salah satu instrumen investasi favorit karena nilainya yang selalu naik dari tahun ke tahun. Nilai emas terhadap rupiah dan terhadap mata uang lain berfluktuasi setiap saat. Namun jika melihat jangka panjang, nilai emas terhadap mata uang rupiah selalu naik. Sebagai contoh, emas Antam per gram pada tahun 2010 berada dikisaran harga Rp350 ribu, sekarang ditahun 2017 per gram harga emas Antam sudah mencapai Rp650 ribu rupiah. Bisa dikatakan bahwa dalam 7 tahun saja harga emas naik hampir dua kali lipat. Kelebihan emas inilah yang membuat investor melirik untuk melakukan investasi pada emas. Tetapi investasi emas juga memiliki kekurangan yaitu harus disimpan ditempat yang aman, karena nilainya yang tinggi. Untuk melakukan penyimpanan emas dapat menyewa safety deposit box di bank atau instansi yang berhak melakukan perdagangan emas.

Saham merupakan salah satu investasi yang sudah cukup lama dikenal oleh masyarakat Indonesia. Indeks Harga Saham Gabungan (biasa disebut IHSG) merupakan salah satu indeks pasar saham yang digunakan di Bursa Efek Indonesia (BEI). Diperkenalkan pertama kali pada tanggal 1 April 1983, sebagai indikator pergerakan harga saham di BEJ, Indeks ini mencakup pergerakan harga seluruh saham biasa dan saham preferen yang tercatat di BEI.

Saham adalah sertifikat kepemilikan atas perusahaan. Bahkan informasi saham dapat diketahui melalui media cetak dan elektronik yang meliputi informasi pergerakan harga dan rumor yang beredar. Kelebihan dari investasi saham biasa adalah kemampuannya untuk memberikan keuntungan atau rate of return yang tidak terhingga. Saham dapat memberikan keuntungan dengan pembagian keuntungan perusahaan kepada para pemegang saham yang disebut deviden. Disamping mendapat penghasilan dari deviden, pemilik saham juga 
memiliki kemungkinan mendapatkan penghasilan dari capital gain. Capital gain adalah keuntungan yang diperoleh dari selisih harga jual kembali saham yang lebih besar dibanding dengan harga belinya.

\section{Pokok Masalah}

Berdasarkan penjelasan diatas maka didapatkan pokok masalah: bagaimana memilih investasi yang terbaik antara emas atau IHSG dalam jangka waktu 1 tahun, 5 tahun, dan 10 tahun. Berdasarkan penjelasan diatas maka didapatkan pokok masalah: bagaimana memilih investasi yang terbaik antara emas atau IHSG dalam jangka waktu 1 tahun, 5 tahun, dan 10 tahun.

\section{Tujuan, Ruang Lingkup, dan Manfaat Penelitian}

Tujuan dari penelitian ini adalah untuk mengetahui perbandingan investasi antara emas dengan IHSG. Dengan adanya penelitian ini diharapkan para pembaca dapat memilih dan merencanakan instrumen investasi mana yang terbaik untuk jangka pendek (selama 1 tahun), jangka menengah (selama 5 tahun), dan jangka panjang (selama 10 tahun).

\section{TELAAH KEPUSTAKAAN}

\section{Landasan Teori \\ Definisi Emas}

Emas digunakan sebagai standar keuangan di banyak negara dan juga sebagai alat tukar yang relatif abadi, dan diterima di semua negara di dunia. Penggunaan emas dalam bidang moneter dan keuangan berdasarkan nilai moneter absolut dari emas itu sendiri terhadap berbagai mata uang di seluruh dunia, meskipun secara resmi di bursa komoditas dunia, harga emas dicantumkan dalam mata uang dolar Amerika. Bentuk penggunaan emas dalam bidang moneter lazimnya berupa batangan emas dalam berbagai satuan berat gram sampai kilogram.

\section{Faktor -faktor yang Mempengaruhi Harga Emas}

Faktor-faktor yang mempengaruhi harga emas menurut (Abdullah, 2013) adalah:

- Inflasi yang Meningkat Melebihi Prediksi.

- Kericuhan Finansial. Krisis moneter pada tahun 1998 dan 2008 termasuk kedalam kericuhan atau kepanikan finansial.

- Kenaikan Harga Minyak yang Siginifikan.

- Permintaan Emas. Harga emas akan terus naik jika permintaan emas dunia yg terus naik berbanding terbalik dengan pasokan emas yang ada.

- Kondisi Politik di Dunia. Ketidakpastian ekonomi adalah akibat dari suhu politik dunia yang tinggi karena ketegangan yang terjadi antar negara-negara di dunia.

- Perubahan kurs. Melemahnya kurs dollar AS dapat mendorong kenaikan harga emas dunia.

\section{Jenis-jenis Investasi Emas}

Emas adalah salah satu kekayaan alam yang tidak dapat diperbaharui, volume emas di dunia terbatas dan mengakibatkan harga emas cenderung stabil dan cenderung meningkat dari tahun ke tahun. Ada 3 jenis investasi emas, yaitu :

- Investasi emas dalam bentuk fisik

- Investasi Emas dalam bentuk perhiasan

- Investasi Emas dalam bentuk satuan trading

\section{Definisi Investasi}

Investasi pada hakikatnya merupakan penempatan sejumlah dana dengan harapan memperoleh keuntungan di masa mendatang (Halim 2005:4) atau investasi juga dapat 
didefenisikan sebagai bentuk pengelolaan dana untuk memberikan keuntungan dengan cara menempatkan dana pada alokasi yang diperkirakan akan memberikan tambahan keuntungan atau coumpounding (Fahmi 2006:2). Dalam Kamus Besar Indonesia (KBBI) disebutkan yang dimaksud dengan investasi berarti : (1) penanaman uang atau modal di suatu perusahaan atau proyek untuk tujuan memperoleh keuntungan, dan (2) jumlah uang atau modal yang ditanam.

\section{Tujuan Investasi}

Ada beberapa alasan mengapa seseorang melakukan investasi, kamarudin ahmad mengemukakan tiga alasan sehingga banyak orang melakukan investasi antara lain adalah :

- Untuk mendapat kehidupan yang lebih layak di masa datang.

- Mengurangi tekanan inflasi.

- Dorongan untuk menghemat pajak.

\section{Definisi Saham}

Saham dapat didefinisikan sebagai surat berharga sebagai bukti penyertaan atau kepemilikan individu maupun institusi dalam perusahaan (Brigham, 2006:58). Saham berwujud selembar kertas yang menerangkan bahwa pemilik kertas adalah pemilik perusahaan yang menerbitkan surat berharga tersebut. Porsi kepemilikan ditentukan oleh seberapa besar penyertaan yang ditanamkan di perusahaan tersebut. Saham merupakan salah satu dari beberapa alternatif yang dapat dipilih untuk berinvestasi.

\section{Penelitian Terdahulu}

Berdasarkan penelitian sebelumnya yang dilakukan oleh Sisca Debyola Widuhung (2014) yang meneliti perbandingan return dan risiko investasi pada saham syariah dan emas didapatkan bahwa investasi emas menghasilkan return lebih tinggi dibanding saham syariah. Berdasarkan penelitian sebelumnya yang dilakukan oleh Amin Hudaya dan Natali Yustisia (2013) yang meneliti perbandingan kinerja emas dan IHSG didapatkan bahwa emas menghasilkan return lebih tinggi dibandingkan IHSG.

\section{Kerangka Pemikiran}

Kerangka pemikiran untuk penelitian ini dapat dijelaskan secara singkat melalui gambar dibawah ini

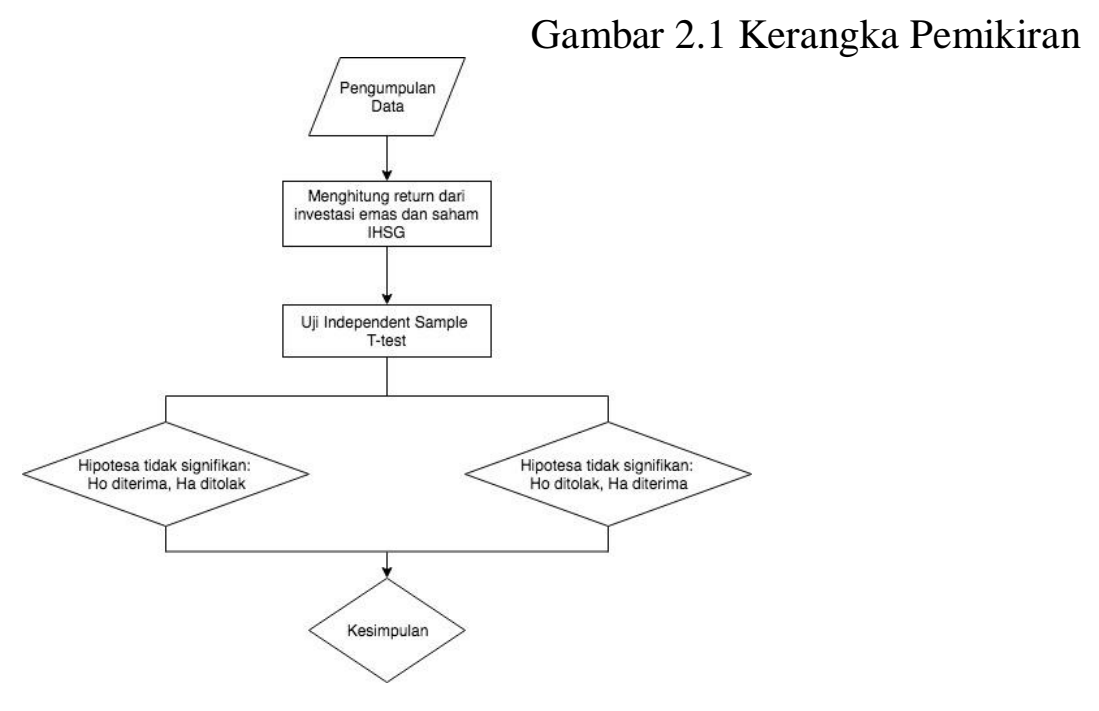

\section{Hipotesis Penelitian}

Karena pada penelitian ini membandingkan 2 instrumen investasi, maka digunakan hipotesis komparatif. Rumusan masalah komparatif: 
- Bagaimana perbandingan pengembalian nilai investasi antara emas dengan IHSG dalam jangka waktu 1 tahun?

- Bagaimana perbandingan pengembalian nilai investasi antara emas dengan IHSG dalam jangka waktu 5 tahun?

- Bagaimana perbandingan pengembalian nilai investasi antara emas dengan IHSG dalam jangka waktu 10 tahun?

Hipotesis komparatif: berdasarkan rumusan masalah komparatif diatas dapat dikemukakan 3 model hipotesis sebagai berikut:

- hipotesis 1

$>$ Ho : Tidak terdapat perbedaan pengembalian nilai investasi antara emas dengan IHSG dalam jangka waktu 1 tahun

$>\mathrm{Ha}$ : Terdapat perbedaan pengembalian nilai investasi antara emas dengan IHSG dalam jangka waktu 1 tahun

- $\quad$ hipotesis 2

$>$ Ho : Tidak terdapat perbedaan pengembalian nilai investasi antara emas dengan IHSG dalam jangka waktu 5 tahun

$>\mathrm{Ha}$ : Terdapat perbedaan pengembalian nilai investasi antara emas dengan IHSG dalam jangka waktu 5 tahun

- $\quad$ hipotesis 3

$>$ Ho : Tidak terdapat perbedaan pengembalian nilai investasi antara emas dengan IHSG dalam jangka waktu 10 tahun

Ha : Terdapat perbedaan pengembalian nilai investasi antara emas dengan IHSG dalam jangka waktu 10 tahun

\section{METODOLOGI PENELITIAN}

\section{Jenis dan Periode Penelitian}

Periode pengambilan data mengambil data 10 tahun terakhir yaitu dari November 2009 sampai Oktober 2018. Jenis data yang diambil adalah data rata-rata harga penutupan yang diperdagangkan untuk instrumen investasi tersebut dalam waktu 1 minggu.

\section{Sumber dan Pengumpulan Data}

Sumber data untuk penelitian ini akan menggunakan data yang berasal dari gold.org untuk harga historical emas, dan finance.yahoo.com untuk harga IHSG.

\section{Variabel Penelitian}

Variabel yang digunakan untuk penelitian kali ini hanya satu yaitu pengembalian investasi. Pengembalian investasi merupakan nilai dari selisih antara harga jual kembali (Buyback Price) pada periode t dengan harga beli (Buy Price) pada periode sebelumnya (t-1). Untuk menghitung pengembalian investasi digunakan rumus:

Pengembalian Investasi $=$

$$
\frac{P_{t}-P_{t-1}}{P_{t=1}}
$$

Keterangan:

$\mathrm{Pt} \quad=$ Harga jual kembali emas periode sekarang

$\mathrm{P}_{\mathrm{t}-1} \quad=$ Harga beli emas periode sebelumnya 
Pengujian pada penelitian ini menggunakan uji-t (independent sample $t$ test) yang bertujuan untuk mengetahui apakah ada perbedaan return dalam berinvestasi pada emas dan IHSG. Selain itu, untuk mengetahui investasi mana yang memiliki return lebih tinggi.

\section{ANALISIS DAN BAHASAN TEMUAN}

\section{Analisis Deskriptif}

Return merupakan salah satu faktor utama untuk investor dalam berinvestasi atau imbalan atas keberanian investor menanggung risiko atas investasi yang dilakukannya. Selama periode penelitian November 2017 - Oktober 2018, tingkat pengembalian return rata-rata emas sebesar 0.000934, sedangkan tingkat pengembalian return rata-rata IHSG sebesar 0.000254. Return emas tertinggi terjadi pada tanggal 26 Maret 2018 sebesar 0.028457 . Return emas terendah terjadi pada tanggal 2 April 2018 sebesar -0.020042 (Loss). Return IHSG tertinggi terjadi pada tanggal 11 Juni 2018 sebesar 0.028457. Return emas terendah terjadi pada tanggal 2 April 2018 sebesar -0.066027 (Loss).

\section{Uji Normalitas}

Uji normalitas bertujuan untuk menguji apakah data berdistribusi normal atau tidak. Untuk mendeteksi normalitas data dilakukan dengan menggunakan Kolmogrov-smirnov. Hasil uji normalitas menggunakan Kolmogrov-smirnov adalah sebagai berikut:

Tabel 4.1 uji normalitas emas

\begin{tabular}{|c|c|c|}
\hline & & Return \\
\hline$N$ & & 471 \\
\hline \multirow[t]{2}{*}{ Normal Parameters } & Mean & ,001558 \\
\hline & std. Deviation & ,020945 \\
\hline \multirow[t]{3}{*}{ Most Extreme Differences } & Absolute & ,056311 \\
\hline & Positive & ,049260 \\
\hline & Negative &,- 056311 \\
\hline Kolmogorov-Smirnov Z & & 1,222085 \\
\hline Asymp. Sig. (2-tailed) & & ,083 \\
\hline
\end{tabular}

Dari tabel 4.1 diketahui bahwa nilai kolmogrov-smirnov untuk kategori return investasi emas sebesar 1.222085 dengan probabilitas signifikansi 0.83. Dari tes ini menunjukkan bahwa nilai return investasi emas jauh diatas 0,05 dan menunjukkan bahwa data untuk return investasi emas adalah berdistribusi normal.

Tabel 4.2 uji normalitas saham

\begin{tabular}{|c|c|c|}
\hline & & Return \\
\hline$N$ & & 467 \\
\hline \multirow[t]{2}{*}{ Normal Parameters } & Mean & ,002053 \\
\hline & Std. Deviation & ,022248 \\
\hline \multirow[t]{3}{*}{ Most Extreme Differences } & Absolute & ,081163 \\
\hline & Positive & ,063110 \\
\hline & Negative &,- 081163 \\
\hline Kolmogorov-Smirnov Z & & 1,753937 \\
\hline Asymp. Sig. (2-tailed) & &, 002 \\
\hline
\end{tabular}

Dari tabel 4.2 diketahui bahwa nilai kolmogrov-smirnov untuk kategori return investasi IHSG sebesar 1.753937 dengan probabilitas signifikansi 0.02. Dari tes ini menunjukkan bahwa nilai return investasi emas berada dibawah 0,05 . Hal ini menunjukkan bahwa data untuk return investasi IHSG berdistribusi tidak normal.

\section{Analisis Statistik}

Analisis statistik digunakan untuk membuktikan hipotesis penelitian. Uji statistik yang digunakan dalam penelitian ini adalah uji-t (independent sample t test). Metode uji beda ratarata dua sampel yang berbeda merupakan prosedur untuk membandingkan rata-rata dua sampel yang berbeda. Yang diolah melalui progam PSPP 1.2.0. 
Tabel 4.3 statistik grup jangka waktu 1 tahun

\begin{tabular}{|c|c|c|c|c|c|}
\hline & Variabel & $N$ & Mean & Std. Deviation & S.E. Mean \\
\hline Return & $\begin{array}{l}\text { emas } \\
\text { saham }\end{array}$ & $\begin{array}{l}54 \\
53\end{array}$ & $\begin{array}{r}.000934 \\
-.000254\end{array}$ & $\begin{array}{l}.010668 \\
.020712\end{array}$ & $\begin{array}{l}.001452 \\
.002845\end{array}$ \\
\hline
\end{tabular}

Tabel 4.4 independent sample test jangka waktu 1 tahun

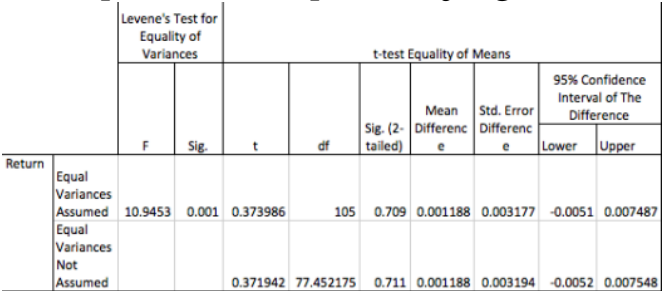

Dari tabel 4.3 dapat dilihat bahwa hasil pengujian dengan independent sample t-test menunjukkan nilai rata-rata tingkat pengembalian return emas sebesar 0.000934, sedangkan nilai rata-rata tingkat pengembalian return IHSG sebesar -0,000254. Berdasarkan hasil tersebut, maka tingkat pengembalian return rata-rata emas lebih besar dibandingkan tingkat pengembalian return IHSG untuk jangka waktu 1 tahun dari November 2017 - Oktober 2018. Perbedaan tingkat pengembalian return kedua instrumen investasi adalah sebesar 0.001188 .

Tabel 4.4 menunjukkan bahwa nilai signifikansi sebesar 0.709 yang mana lebih besar dari 0.05, sehingga dapat disimpulkan untuk periode 1 tahun dari November 2017 - Oktober 2018 Ho diterima. Dengan demikian tidak ada perbedaan yang signifikan antara return investasi emas dengan return investasi IHSG dalam periode 1 tahun dari November 2017 Oktober 2018.

Tabel 4.5 statistik grup jangka waktu 5 tahun

\begin{tabular}{|l|l|c|c|r|r|}
\hline \multicolumn{2}{|c|}{ Variabel } & $N$ & \multicolumn{1}{c|}{ Mean } & Std. Deviation & S.E. Mean \\
\hline \hline Return & emas & 210 & .001089 & .017495 & .001207 \\
& saham & 207 & .000913 & .019148 & .001331 \\
\hline
\end{tabular}

Tabel 4.6 independent sample test jangka waktu 5 tahun

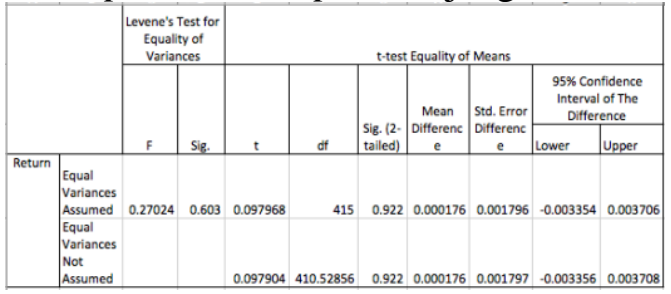

Dari tabel 4.5 dapat dilihat bahwa hasil pengujian dengan independent sample t-test menunjukkan nilai rata-rata tingkat pengembalian return emas sebesar 0.001089, sedangkan nilai rata-rata tingkat pengembalian return IHSG sebesar 0,000913. Berdasarkan hasil tersebut, maka tingkat pengembalian return rata-rata emas lebih besar dibandingkan tingkat pengembalian return IHSG untuk jangka waktu 5 tahun dari November 2014 - Oktober 2018. Perbedaan tingkat pengembalian return kedua instrumen investasi adalah sebesar 0.000176 .

Tabel 4.6 menunjukkan bahwa nilai signifikansi sebesar 0.922 yang mana lebih besar dari 0.05, sehingga dapat disimpulkan untuk periode 5 tahun dari November 2014 - Oktober 2018 Ho diterima. Dengan demikian tidak ada perbedaan yang signifikan antara return investasi emas dengan return investasi IHSG dalam periode 5 tahun dari November 2014 Oktober 2018.

Tabel 4.7 statistik grup jangka waktu 10 tahun

\begin{tabular}{|c|c|c|c|c|c|}
\hline вยпाш & $\begin{array}{l}\text { 29ugw } \\
\text { 6wse }\end{array}$ & $\begin{array}{l}251 \\
253\end{array}$ & $\begin{array}{r}005552 \\
001518\end{array}$ & $\begin{array}{l}.05 \triangle 28 \mathrm{~S} \\
0538 \triangle 8\end{array}$ & $\begin{array}{l}001042 \\
001272\end{array}$ \\
\hline & $\Lambda_{\text {sulgpe }}$ & & WGSU & 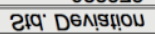 & 2. WGSU \\
\hline
\end{tabular}

Tabel 4.8 independent sample test jangka waktu 10 tahun 


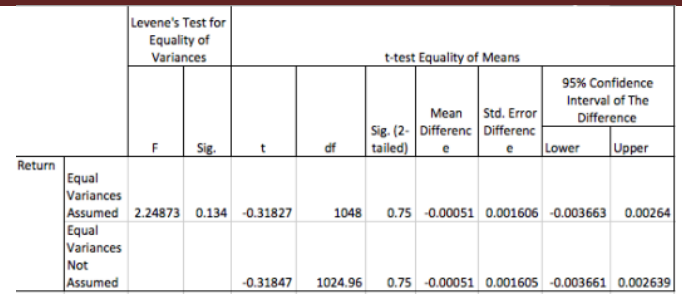

Dari tabel 4.7 dapat dilihat bahwa hasil pengujian dengan independent sample t-test menunjukkan nilai rata-rata tingkat pengembalian return emas sebesar 0.001718, sedangkan nilai rata-rata tingkat pengembalian return IHSG sebesar 0,002229. Berdasarkan hasil tersebut, maka tingkat pengembalian return rata-rata emas lebih kecil dibandingkan tingkat pengembalian return IHSG untuk jangka waktu 10 tahun dari November 2009 - Oktober 2018. Perbedaan tingkat pengembalian return kedua instrumen investasi adalah sebesar 0.000511 .

Tabel 4.8 menunjukkan bahwa nilai signifikansi sebesar 0.75 yang mana lebih besar dari 0.05, sehingga dapat disimpulkan untuk periode 10 tahun dari November 2009 - Oktober 2018 Ho diterima. Dengan demikian tidak ada perbedaan yang signifikan antara return investasi emas dengan return investasi IHSG dalam periode 10 tahun dari November 2009 Oktober 2018.

\section{KESIMPULAN DAN SARAN}

\section{Kesimpulan}

Dari penelitian ini didapatkan bahwa investasi untuk jangka pendek (1 tahun) periode November 2017 sampai Oktober 2018 investasi emas lebih menguntungkan dari investasi IHSG. Sedangkan untuk jangka menengah (5 tahun) periode November 2014 sampai Oktober 2018 investasi emas masih lebih menguntungkan dari investasi IHSG. Tetapi untuk jangka panjang (10 tahun) periode November 2009 sampai Oktober 2018 investasi IHSG lebih menguntungkan dari investasi emas. Dan berdasarkan uji-t (independent sample $t$ test) terhadap ketiga periode, didapatkan hasil bahwa tidak ada perbedaan signifikan antara return investasi emas dengan return investasi saham.

\section{Saran}

Saran untuk penelitian selanjutnya agar dapat menambahkan variabel instrumen investasi yang terkenal lebih banyak agar dapat membantu investor dalam menentukan pilihan investasi. Dalam penelitian selanjutnya bisa juga menambahkan risiko investasi agar dapat menjadi pertimbangan investor dalam berinvestasi, karena return hanyalah salah satu faktor untuk berinvestasi.

\section{DAFTAR PUSTAKA}

[1] Baur, Dirk G., Brian M Lucey. 2010. Is Gold a Hedge or a Safe Haven? An Analysis of Stocks, Bonds and Gold. The Financial Review (217- 229).

[2] Bodie, Zvi et als. 2011. Investments and PortofolioManagement. Ninth Edition. Mc Graw Hill International Edition.

[3] Iqbal, Muhaimin. 2009. Dinar The Real Money: Dinar Emas, Uang \& Investasiku. Jakarta: Gema Insani

[4] Gunawan, Adhitya I, dan Ni Gusti Putu Irawati. 2013. Perbandingan Berinvestasi Antara Logam Mulia Emas Dengan Saham Perusahaan Pertambangan Emas.

[5] Gunawan, Adhitya I, dan Ni Gusti Putu Irawati. 2013. Perbandingan Berinvestasi Antara Logam Mulia Emas Dengan Saham Perusahaan Pertambangan Emas. 
[6] Bodie, kane, marcus. 2006. Investments Buku 1 dan buku 2, edisi 6. Salemba Empat: Jakarta.

[7] Sisca Debyola Widuhung. 2014. Perbandingan Return dan Risiko Investasi pada Saham Syariah dan Emas

[8] Asri Nur Wahyuni. 2014. Analisis Perbandingan Kinerja Investasi Emas dan Investasi Saham selama Masa Inflasi 1994 - 2013

[9] Beta Eviana Rohmahningrum. 2018. Analisi Perbandingan Rerturn Investasi Saham dengan Emas di PT ANEKA TAMBANG TBK

[10] Amin Hudaya dan Natali Yustisia. 2013. Analisis Perbandingan Kinerja Emas dengan Indeks Harga Saham Gabungan (IHSG)

Website:

https://goldprice.org/id/gold-price-chart.html

http://widhiarso.staff.ugm.ac.id/files/membaca_t-tes.pdf

http://duwiconsultant.blogspot.com/2011/11/independent-samples-t-test.html

https://eriskusnadi.wordpress.com/2012/04/07/uji-normalitas-dengan-kolmogorov-smirnovtest-pada-pspp/

https://www.statistikian.com/2014/04/independen-t-test-dengan-spss.html

https://www.gomarketingstrategic.com/pengertian-indeks-harga-saham-gabungan-ihsg/

https://analis.co.id/ihsg-indeks-harga-saham-gabungan.html

https://www.orori.com/ororeads/12-jenis-investasi-emas 
